\title{
Microenvironment engineering of Ru nanoparticles incorporated in silica nanoreactors for enhanced hydrogenations
}

\author{
Xiaomin Ren, ${ }^{[a, b]}$ Miao Guo, ${ }^{\dagger[a]} \mathrm{He} \mathrm{Li}^{\left[{ }^{[a]}\right.}$ Chengbin Li, ${ }^{[a]}$ Liang Yu, ${ }^{*[a]}$ Jian Liu*[a,c] and Qihua Yang*[a] \\ Dedicated to the 70th anniversary of the Dalian Institute of Chemical Physics, Chinese Academy of Sciences
}

\begin{abstract}
It is a challenging task to promote the activity and selectivity of a catalyst via precisely engineering the microenvironment, an important factor related with the catalytic performance of natural catalysts. Motivated by the water effect in promoting the catalytic activity explored in this work, we reported that the nanoreactor modified with phosphine ligand enabled the efficient hydrogenation of benzoic acid (BA) over Ru nanoparticles (NPs) in organic solvent under mild conditions, which cannot be achieved in unmodified nanoreactors. Both density functional theory (DFT) calculations and catalytic performance tests showcased that the phosphine ligands can manipulate the adsorption strength of BA on Ru NPs by tuning the surface properties as well as preferentially interacting with the carboxyl of BA. The insights obtained in the present study provide a novel concept of nanoreactor design via anchoring ligands near catalytic active centers.
\end{abstract}

Enzymes, the natural catalysts, can efficiently catalyze the chemical reactions under mild conditions to afford both high activity and high chemo/stereo/chiral selectivity. In comparison, metal complexes possessing with similar molecular structures to the active sites of enzymes do not always show high activity and selectivity. ${ }^{[1]}$ This is due to the loss of specific microenvironment around the active sites. ${ }^{[1-2]}$ Previous investigations suggest that amino acid residues around the catalytic active sites of enzymes could assist enriching, organizing and activating substrates via non-covalent interactions. ${ }^{[3]}$

Supported metal nanoparticles are an important class of catalyst materials and have been widely used in industries for various chemical reactions, such as hydrogenation, oxidation, CC coupling and isomerization. ${ }^{[4-8]}$ Generally, the catalytic performance of metal NPs can be modulated by modifying its physicochemical properties such as, the size, shape and interactions with supports. ${ }^{[4]}$ Additionally, previous investigations

[a] X. Ren, Dr. M. Guo, Dr. H. Li, Dr. C. Li, Dr. L. Yu, Prof. J. Liu, Prof. Q. Yang

State Key Laboratory of Catalysis

iChEM, Dalian Institute of Chemical Physics

Chinese Academy of Sciences

Dalian 116023, China

E-mail: lyu@dicp.ac.cn (LY), yangqh@dicp.ac.cn (QY)

[b] X. Ren

University of Chinese Academy of Sciences

Beijing 100049, China

[c] Prof. J. Liu

DICP-Surrey Joint Centre for Future Materials

Department of Chemical and Process Engineering and Advanced

Technology Institute

University of Surrey

Guildford, Surrey GU2 7XH, UK

E-mail: jian.liu@surrey.ac.uk (JL)

$\uparrow$ These authors contributed equally.

Supporting information for this article is given via a link at the end of the document. have showcased the importance of microenvironments in tuning the catalytic performance of metal NPs by affecting its adsorption energy and adsorption modes of substrates, ${ }^{[9-13]}$ which could be realized via the generating a steric hindrance around metal NPs, ${ }^{[14-17]}$ introducing the binding site with specific functional group near metal NPs, ${ }^{[18-21]}$ and so on.

The catalytic hydrogenation of benzoic acid (BA) is of pivotal importance in industry. However, negligible conversion of BA was obtained in aprotic organic solvents under similar conditions $\left(60{ }^{\circ} \mathrm{C}, 1 \mathrm{MPa}\right)$ over metal NPs. ${ }^{[22-24]}$ Previous studies showed that both activity and selectivity of metal NPs could be improved by the presence of water. ${ }^{[25-27]}$ For example, Anderson and coworkers reported that the hydrogenation of aromatic ring was favoured over carbonyl group using water as solvent and the opposite tendency was observed using cyclohexane as solvent. ${ }^{[28]}$ Recently, Resasco elucidated the alternative hydrogenation path in the presence of water was related with charge separation using of hydrogenation of furfural as model reaction. ${ }^{[29]}$ The promotion effect of water was also observed for BA hydrogenation, but it has not been clarified yet. ${ }^{[22-24]}$

Herein, we reported that silica nanoreactors modified with phosphine ligand behave as high active catalyst for hydrogenations through microenvironment engineering of $\mathrm{Ru}$ nanoparticles. In addition, the acceleration effect of water in the hydrogenation was elucidated by tuning the adsorption mode of BA over Ru NPs.

Strikingly, a sharp increase in the BA conversion from $\sim 0$ to $\sim 50 \%$ was observed over Ru/FDU (Ru loading amount of $3 \mathrm{wt} \%$, FDU refers to FDU-12) when only $1 \mathrm{v} / \mathrm{v} \%$ of water were added into the hexane solvent, followed by a further increase to $~ 99 \%$ conversion as the water content reached to $10 \mathrm{v} / \mathrm{v} \%$ with cyclohexanecarboxylic acid (CCA) as the main reaction product detected (Figure 1A). This acceleration effect of water is consistent with previous reports. ${ }^{[22-24]}$ DFT calculations results show that $\mathrm{H}_{2} \mathrm{O}$ can readily dissociate to $\mathrm{O}^{*}$ and $\mathrm{H}^{*}$ on the $\mathrm{Ru}(0001)$ surface with a free energy gain of $0.97 \mathrm{eV}$ until reaching an equilibrium coverage of $5 / 6$ monolayer (Figure S1). The generated $\mathrm{O}^{*}$ species strongly passivate the $\mathrm{Ru}$ surface, resulting in a significant decrease in the adsorption free energy of $\mathrm{BA}$ from $-1.93 \mathrm{eV}$ on the clean surface to $-1.06 \mathrm{eV}$, which is on the surface covered by $2 / 3$ monolayer of $\mathrm{O}^{*}$ and $\mathrm{H}^{*}$ (Figure $1 \mathrm{~B})$. As a result, the activation barriers of the hydrogenation elementary steps are apparently lowered on the water-mediated $\mathrm{Ru}(0001)$ surface. As shown in the calculated reaction pathway of the hydrogenation of BA (Figure 1C), the first three hydrogenation steps which require relatively higher activation energies $(0.73,0.72$ and $0.91 \mathrm{eV})$ and are rate-limiting on pure $\mathrm{Ru}(0001)$, become much favored with notably decreased activation barriers of $0.33,0.59$, and $0.75 \mathrm{eV}$, respectively, on the surface covered by $2 / 3$ monolayer of water. It is noteworthy that the $\mathrm{H}^{\star}$ from the dissociated $\mathrm{H}_{2} \mathrm{O}$ can also participate in the reaction as the reductant. Therefore, DFT calculations 
demonstrate that the water effect in promoting the reaction kinetics originates from the dissociation of $\mathrm{H}_{2} \mathrm{O}$ on the $\mathrm{Ru}$ surface whereby the generated $\mathrm{O}^{*}$ species weakens the interaction between BA and the catalyst surface and thereby lowers the reaction barriers.
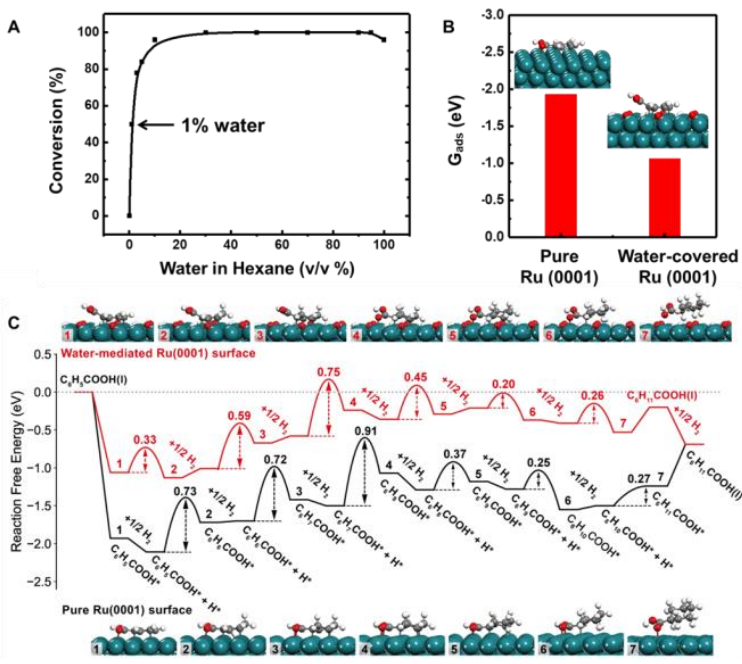

Figure 1. (A) Conversion of $B A$ as a function of solvent composition (water/hexane) over Ru/FDU. (B) Adsorption free energy of BA on pure $\mathrm{Ru}(0001)$ and water-mediated $\mathrm{Ru}(0001)$. (C) DFT calculated reaction paths of BA hydrogenation on water-mediated (red) and pure (black) $R u(0001)$ surfaces. On the water-mediated surface, the first hydrogenation step consumed one $\mathrm{H}^{*}$ of dissociated $\mathrm{H}_{2} \mathrm{O}$. Insets show the atomic structures of reaction intermediates. Red, grey, white, and dark cyan spheres represent $\mathrm{O}$, $\mathrm{C}, \mathrm{H}$, and $\mathrm{Ru}$ atoms, respectively.

Isotopic experiments were then conducted to further validate the dissociation of water over the Ru/FDU catalyst by using $\mathrm{D}_{2} \mathrm{O} / \mathrm{H}_{2}$ or $\mathrm{H}_{2} \mathrm{O} / \mathrm{D}_{2}$ as the solvent/reductant in the hydrogenation of $\mathrm{BA}$ reaction. Isotopic exchange test under $\mathrm{D}_{2} \mathrm{O} / \mathrm{N}_{2}$ excludes the effect of $\mathrm{H} / \mathrm{D}$ exchange between the phenyl group and molecular $\mathrm{D}_{2} \mathrm{O}$ on the $\mathrm{Ru}$ surface (Figure S2). However, as $\mathrm{H}_{2}$ was added into the reaction system, molecular ion peaks at $\mathrm{m} / \mathrm{z}$ 126-132 and 128-134 denoting 1-4 deuterated 1cyclohexenecarboxylic acid (CEA) and 1-6 deuterated CCA, respectively, were clearly observed in the $M S$ spectra of the products in the corresponding $\mathrm{H}_{2} \mathrm{O} / \mathrm{D}_{2}$ and $\mathrm{D}_{2} \mathrm{O} / \mathrm{H}_{2}$ reaction systems. These results confirm the involvement of water molecules in the reaction process via being dissociated on the $\mathrm{Ru}$ surface. The $\mathrm{H}$ source stems from both the dissociated $\mathrm{H}_{2} \mathrm{O}$ (or $\mathrm{D}_{2} \mathrm{O}$ ) and $\mathrm{D}_{2}$ (or $\mathrm{H}_{2}$ ) under aqueous reaction conditions and thereby the hydrogenated products by a combination of $H / D$ were obtained in the isotopic experiments. This further implies the generation of oxygen species from $\mathrm{H}_{2} \mathrm{O}$ dissociation on the $\mathrm{Ru}$ surface which will modify the surface properties and tailor the catalytic activity.

The above results illustrate the significant role of the BA adsorption strength on the catalyst surface in determining the hydrogenation of $\mathrm{BA}$ reaction micro-kinetics and hence the catalytic performance. Therefore, tuning the interaction between the BA and the Ru surface offers a feasible strategy of tailoring the catalytic activity of Ru catalyst in organic solvents.

To tune the interaction between the BA and the Ru surface, organic ligands were incorporated in the nanocages of mesoporous silica FDU, which has been widely used to construct nanoreactors. ${ }^{[30-37]}$ Triphenylphosphine, ethyldiphenylphosphine, propylamine and phenyl groups incorporated FDU were denoted as $\mathrm{PPh}_{3} @ F D U, \mathrm{PPh}_{2}$-FDU,
$\mathrm{NH}_{2}$-FDU and Ph@FDU, respectively. $\mathrm{PPh}_{3} @ \mathrm{FDU}$ and Ph@FDU were prepared by in situ polymerization method with tris(4-vinylphenyl)phosphine and divinylbenzene (DVB) as monomers and AIBN (azobisisobutyronitrile) as the initiator as we previously reported. ${ }^{[38]} \mathrm{PPh}_{2}-\mathrm{FDU}$ and $\mathrm{NH}_{2}$-FDU were prepared by post grafting method with 2(diphenylphosphino)ethyltriethoxysilane and aminopropyltriethoxysilane as silylation reagents (characterization details see $\mathrm{SI}$ ).

$\mathrm{Ru} / \mathrm{PPh}_{3} @ \mathrm{FDU}, \mathrm{Ru} / \mathrm{PPh}_{2}-\mathrm{FDU}, \mathrm{Ru} / \mathrm{Ph} @ \mathrm{FDU}$ and Ru/NH $\mathrm{N}_{2}$ FDU with $3 w t \%$ of Ru NPs were prepared. The high-angle annular dark field scanning transmission electron microscopy (HAADF-STEM) and TEM images clearly showed the particle size of Ru NPs on different supports was similar and distributed at ca. $2.5 \mathrm{~nm}$ by calculating 200 nanoparticles (Figure 2A and Figure S4A). The dispersity of $\mathrm{Ru}$ measured by $\mathrm{CO}$ chemisorption only varied slightly for different catalysts, further verifying the HAADF-STEM and TEM results (Table S2). In the following discussion, the influence of particle size on the catalytic performance of the catalysts could be excluded.

The electronic properties of Ru NPs were analyzed by the Xray photoelectron spectroscopy (XPS) (Figure $2 \mathrm{~B}$ and Table S2). Compared with those of $\mathrm{Ru} / \mathrm{FDU}$, the $\mathrm{Ru} 3 p$ binding energies for $\mathrm{Ru} / \mathrm{PPh}_{3} @ \mathrm{FDU}, \mathrm{Ru} / \mathrm{PPh}_{2}-\mathrm{FDU}$ and $\mathrm{Ru} / \mathrm{NH}_{2}$-FDU showed an obvious red shift, indicating the electron donation from $\mathrm{P}$ (or $\mathrm{N}$ ) to $\mathrm{Ru}$. The electron donating from $\mathrm{P}$ to $\mathrm{Ru}$ NPs was further confirmed by the slight blue shift of the binding energies of $P 2 p$ core level of $\mathrm{Ru} / \mathrm{PPh}_{3} @ \mathrm{FDU}$ in comparison with those of $\mathrm{PPh}_{3} @ F D U$. The similar binding energies of Ru/Ph@FDU and $\mathrm{Ru} /$ FDU suggested the weak interaction between Ru NPs and the phenyl rings. The solid-state ${ }^{31} \mathrm{P}$ MAS NMR spectrum of $\mathrm{Ru} / \mathrm{PPh}_{3} @ \mathrm{FDU}$ gave a new peak at 25.8 ppm assigned to $\mathrm{P}$ atom coordinated with Ru NPs (Figure S5), showing the strong interaction of Ru NPs with phosphine ligands. In comparison with $\mathrm{Ru} / \mathrm{PPh}_{2}-\mathrm{FDU}$, the relatively larger red shift was observed for Ru/PPh ${ }_{3} @ F D U(1.0 \mathrm{eV}$ vs. $0.3 \mathrm{eV})$, demonstrating that $\mathrm{PPh}_{3}$ might donate more electrons to Ru NPs. As shown in Table S2, the deconvoluted XPS data suggested that $\mathrm{Ru} / \mathrm{PPh}_{3} @ \mathrm{FDU}$, $\mathrm{Ru} / \mathrm{PPh}_{2}-\mathrm{FDU}$ and $\mathrm{Ru} / \mathrm{NH}_{2}-\mathrm{FDU}$ have higher $\mathrm{Ru}^{\mathrm{o}} / \mathrm{Ru}^{\mathrm{n}+}$ ratio than $\mathrm{Ru} / \mathrm{Ph} @ F D U$ and Ru/FDU, possibly due to the electron donation effect of $\mathrm{P}(\mathrm{N})$.

The surface structure of Ru NPs in different silica nanocages was investigated using in situ FT-IR of $\mathrm{CO}$ adsorption (Figure 2C). The $\mathrm{CO}$ adsorption on Ru/FDU was quite complicated with the bands at 2132 and $2076 \mathrm{~cm}^{-1}$ assigned to $\mathrm{CO}$ bonded on $\mathrm{Ru}^{\mathrm{n+}}$, the band at $2026 \mathrm{~cm}^{-1}$ derived from linear $\mathrm{CO}$ on $\mathrm{Ru}^{0}$ surrounded by $\mathrm{Ru}^{\mathrm{n}+}$, and the broad band at $1960 \mathrm{~cm}^{-1}$ for the bridge-bonded $\mathrm{CO}$ on $\mathrm{Ru}^{0}{ }^{0}{ }^{39,}{ }^{40]}$ The in-situ FT-IR spectra were almost the same for Ru/FDU and Ru/Ph@FDU, indicating that the two catalysts have similar surface structure. Compared with Ru/FDU and Ru/Ph@FDU, the red-shifts of linear-bonded CO were clearly observed for Ru/PPh ${ }_{3} @ F D U, R u / P P h_{2}-F D U$ and $\mathrm{Ru} / \mathrm{NH}_{2}-\mathrm{FDU}$ due to the electron donating from $\mathrm{P}(\mathrm{N})$ to $\mathrm{Ru} N P s$. For the linear $\mathrm{CO}$ adsorbed on Ru surface, the red shifts of 32 , 19 and 9 wavenumbers were observed for Ru/PPh ${ }_{3} @ F D U$, $\mathrm{Ru} / \mathrm{NH}_{2}-\mathrm{FDU}$, and $\mathrm{Ru} / \mathrm{PPh}_{2}-\mathrm{FDU}$, respectively, the negative charges on Ru NPs decreased in the order of Ru/PPh ${ }_{3} @ F D U ~>~$ $\mathrm{Ru} / \mathrm{NH}_{2}-\mathrm{FDU}>\mathrm{Ru} / \mathrm{PPh}_{2}$-FDU > Ru/Ph@FDU $\approx \mathrm{Ru} / \mathrm{FDU}$. The results of XPS and in situ FT-IR characterization showed that $R u$ $\mathrm{NPs}$ in $\mathrm{PPh}_{3} @ \mathrm{FDU}$ had more negative charges than those in $\mathrm{PPh}_{2}-\mathrm{FDU}$ though they had similar $\mathrm{P}$ content. This is probably related with the flexible polymer network and the different 


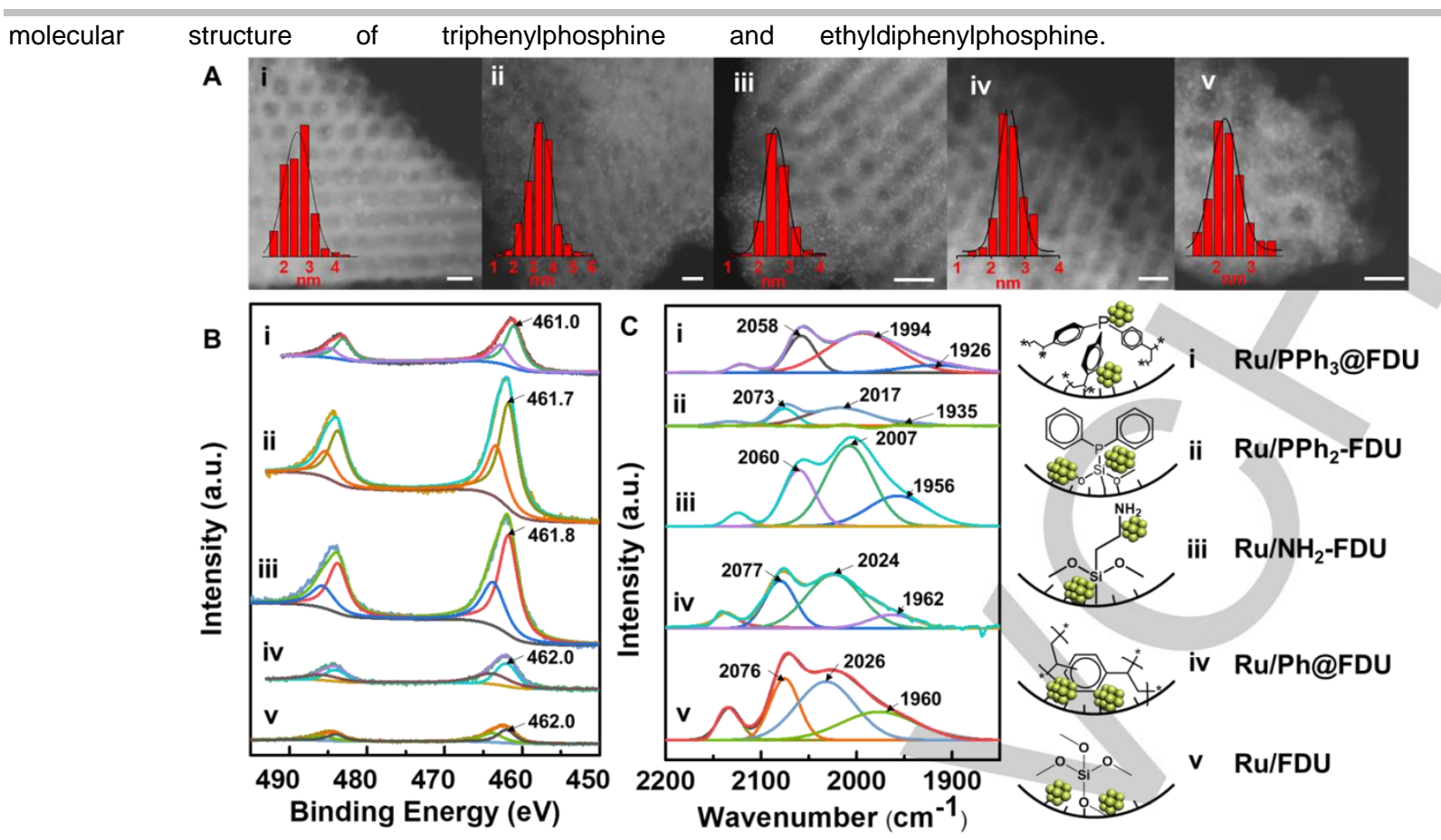

Figure 2 (A) HAADF-STEM images (insets for Ru particle size distributions, scale bar is $20 \mathrm{~nm}$ ), (B) Ru 3p XPS core level spectra, (C) in situ FT-IR spectra of CO adsorption on Ru NPs in nanocages of FDU modified with and without organic ligand.

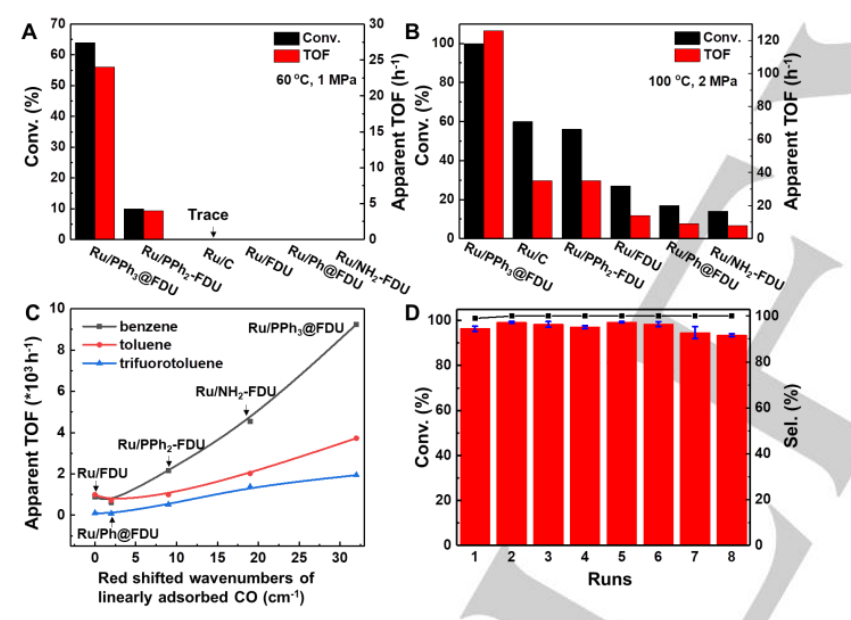

Figure 3. $(A, B)$ The catalytic performance of Ru NPs in hydrogenation of BA using hexane as solvent. (C) Relation of apparent TOF with the red shifted wavenumbers of linearly adsorbed $\mathrm{CO}$ of Ru NPs in hydrogenation of benzene, toluene, and trifluorotoluene under neat condition. (D) Recycling stability of $\mathrm{Ru} / \mathrm{PPh}_{3} @ \mathrm{FDU}$ in BA hydrogenation reaction.

The catalytic performance of $\mathrm{Ru}$ NPs was tested in BA hydrogenation to CCA in hexane, which is a very important organic intermediate. ${ }^{[41,42]}$ At $60^{\circ} \mathrm{C}, 1 \mathrm{MPa} \mathrm{H}_{2}$, no conversion of BA could be found over Ru/ $\mathrm{NH}_{2}-\mathrm{FDU}, \mathrm{Ru} / \mathrm{Ph} @ F D U, R u / F D U$ and commercial $\mathrm{Ru} / \mathrm{C}$, showing that these catalysts were inactive under current conditions (Figure 3A). This is consistent with previous reports that metal NPs were generally inactive for the hydrogenation of $B A$ in aprotic organic solvents under mild reaction conditions. ${ }^{[22-24]}$ Encouragingly, the CCA product was detected with Ru/PPh ${ }_{3} @ F D U$ and Ru/PPh ${ }_{2}$-FDU as catalysts. In addition to CCA, CEA was detected as the only intermediate because BA hydrogenation is a typical stepwise reaction, similar with benzene hydrogenation. ${ }^{[43]} \mathrm{Ru} / \mathrm{PPh}_{3} @ F D U$ afforded 64\% conversion with $98 \%$ selectivity to CCA and $97 \%$ conversion could be obtained by prolonging reaction time to $8 \mathrm{~h}$. Under similar reaction conditions, $\mathrm{Ru} / \mathrm{PPh}_{2}$-FDU with conversion of $10 \%$ gave more inferior activity than Ru/PPh ${ }_{3} @ F D U$. Under more hash reaction conditions (e.g. $2 \mathrm{MPa} \mathrm{H}_{2}, 100^{\circ} \mathrm{C}$ ), other catalysts showed activity for the hydrogenation of BA (Figure 3B). Even under harsh reaction conditions, the TOF decreased in the order of $\mathrm{Ru} / \mathrm{PPh}_{3} @ \mathrm{FDU}>\mathrm{Ru} / \mathrm{C} \approx \mathrm{Ru} / \mathrm{PPh}_{2}$-FDU > Ru/FDU > $\mathrm{Ru} / \mathrm{Ph} @ \mathrm{FDU} \approx \mathrm{Ru} / \mathrm{NH}_{2}-\mathrm{FDU}$. To the best of our knowledge, such high activity has rarely been obtained on metal NPs for BA hydrogenation in aprotic organic solvents. As reported previously, the organic additives were usually added in the catalytic system to modify the catalytic performance of metal NPs. ${ }^{[44]}$ A control experiment was performed for BA hydrogenation over Ru/FDU with $\mathrm{PPh}_{3}$ as the additive in hexane. However, almost no conversion was observed, possibly due to the capping of the active sites on the surface of Ru NPs by $\mathrm{PPh}_{3}$, which is generally observed for reaction systems with organic compounds as additives. This indicates that $\mathrm{PPh}_{3} @ \mathrm{FDU}$ provided a unique microenvironment for Ru NPs.

It is quite interesting that only Ru/PPh ${ }_{3} @ F D U$ and $\mathrm{Ru} / \mathrm{PPh}_{2-}$ FDU showed activity in BA hydrogenation using hexane as the solvent under mild reaction conditions. The organic ligands not only had different interaction strength with BA but also changed the surface electronic structure of Ru NPs. To discern the key factors for influencing the catalytic performance of Ru NPs in BA hydrogenation, aromatic substrates (benzene, toluene and trifluorotoluene) that do not have carboxyl groups were employed to elucidate the influence of the surface electronic structure on the catalytic performance of Ru NPs. All the catalysts are active for the hydrogenation of benzene, toluene and trifluorotoluene under current reaction conditions (Table 1). For the above-mentioned substrates, the catalytic activity decreased in the order of $\mathrm{Ru} / \mathrm{PPh}_{3} @ F D U>\mathrm{Ru} / \mathrm{NH}_{2}$-FDU > $\mathrm{Ru} / \mathrm{PPh}_{2}-\mathrm{FDU}>\mathrm{Ru} / \mathrm{FDU}>\mathrm{Ru} / \mathrm{Ph} @ F D U$. No direct correlation of the activity could be found with the BET surface area and 
surface hydrophilicity/hydrophobicity of the catalysts (Figure S4B), implying that the physical parameters were not the main determining factors for the variation of the activity. As shown in Figure $3 \mathrm{C}$, there is an obvious relation of TOF with the red shifted wavenumbers of linearly adsorbed CO on Ru NPs. The $\mathrm{Ru}$ NPs with higher red-shifts wavenumbers afforded higher TOF, implying that higher negatively-charged surface is advantageous for the hydrogenation of aromatic rings. This indicates that the surface electronic structure of Ru NPs may be the main factors influencing their catalytic activity in the hydrogenation of benzene, toluene and trifluorotoluene. The DFT calculations show that the adsorption free energy benzene on Ru surface decreased with increasing Ru surface electrons, thus suggesting that the surface charge enrichment favor high activity (Figure S6A). It should be noticed that Ru/PPh ${ }_{3} @ F D U$ is even more active than commercial $\mathrm{Ru} / \mathrm{C}$ in the hydrogenation of the above aromatic substrates, confirming the positive effect of $\mathrm{PPh}_{3}$ ligands in promotion of the catalytic activity of Ru NPs.

Table 1. The catalytic performance of Ru NPs in different silica nanocages for the hydrogenation of arenes. ${ }^{[a]}$

\begin{tabular}{|c|c|c|c|c|c|c|}
\hline \multirow{2}{*}{ Cat. } & \multicolumn{2}{|c|}{ Benzene } & \multicolumn{2}{|c|}{ Toluene } & \multicolumn{2}{|c|}{ Trifluorotoluene } \\
\hline & $\begin{array}{c}\text { Conv. } \\
(\%)\end{array}$ & $\begin{array}{l}\text { TOF } \\
\left(h^{-1}\right)\end{array}$ & $\begin{array}{c}\text { Conv. } \\
(\%)\end{array}$ & $\begin{array}{l}\text { TOF } \\
\left(h^{-1}\right)\end{array}$ & $\begin{array}{c}\text { Conv. } \\
(\%)\end{array}$ & $\begin{array}{l}\text { TOF } \\
\left(\mathrm{h}^{-1}\right)\end{array}$ \\
\hline Ru/PPh $3 @$ FDU & $>99$ & 9250 & 97 & 3740 & $>99$ & $1940^{[b]}$ \\
\hline $\mathrm{Ru} / \mathrm{PPh}_{2}-\mathrm{FDU}$ & 22 & 2160 & 30 & 998 & 55 & 520 \\
\hline $\mathrm{Ru} / \mathrm{NH}_{2}-\mathrm{FDU}$ & 39 & 4560 & 57 & 2022 & 92 & 1380 \\
\hline Ru/Ph@FDU & 6 & 620 & 22 & 710 & 8 & 76 \\
\hline $\mathrm{Ru} / \mathrm{FDU}$ & 9 & 880 & 28 & 933 & 11 & 106 \\
\hline $\mathrm{Ru} / \mathrm{C}$ & 56 & 6458 & 37 & 1233 & 86 & 1296 \\
\hline
\end{tabular}

[a] Reaction conditions for benzene and toluene hydrogenation: $S / C=10000$, $100{ }^{\circ} \mathrm{C}, 2 \mathrm{MPa} \mathrm{H}$, solvent free, $1 \mathrm{~h}$ for benzene and $3 \mathrm{~h}$ for toluene; Reaction conditions for trifluorotoluene hydrogenation: $\mathrm{S} / \mathrm{C}=1000,100^{\circ} \mathrm{C}, 2 \mathrm{MPa} \mathrm{H}_{2}$ solvent free, $1 \mathrm{~h}$; the apparent TOF was calculated with conversion less than $30 \% ;[b] \mathrm{S} / \mathrm{C}=5000,4 \mathrm{~h}$

The above results showed that the surface negative charges of Ru NPs played a main role in the hydrogenation of aromatic rings without the carboxyl substituent. However, this is not the case for the hydrogenation of BA. Ru/PPh $-\mathrm{FDU}$ and $\mathrm{Ru} / \mathrm{PPh}_{3} @ \mathrm{FDU}$ were active in the hydrogenation of $\mathrm{BA}$. However, $\mathrm{Ru} / \mathrm{NH}_{2}$-FDU with similar electron rich surface did not show any catalytic activity under mild reaction conditions. Thus, the observed activity difference for BA hydrogenation may be related with the organic ligands around $R u$ NPs rather than the surface negative charges of Ru NPs. The phosphine, amine and $\mathrm{Si}-\mathrm{OH}$ could form interactions with the carboxyl group of BA during the catalytic process, which will increase the possibility of $\mathrm{BA}$ adsorption on $\mathrm{Ru}$ surface via the aromatic ring to enhance the activity. The interaction energies of $\mathrm{BA}$ with $\mathrm{PPh}_{3}, \mathrm{NH}_{2}$ and $\mathrm{Si}-\mathrm{OH}$ were calculated, which are of $-0.42 \mathrm{eV},-0.64 \mathrm{eV}$ and $0.36 \mathrm{eV}$, respectively (Figure S6B). The strong interaction of $\mathrm{NH}_{2}$ with BA will cause the difficulty in desorption of CCA from the catalysts and the weak interaction of $\mathrm{Si}-\mathrm{OH}$ with $\mathrm{BA}$ could not induce the orientated adsorption. Consequently, $\mathrm{Ru} / \mathrm{NH}_{2}-\mathrm{FDU}$ and $\mathrm{Ru} / \mathrm{FDU}$ showed no activity in BA hydrogenation in hexane under mild reaction conditions. The phosphine ligands with suitable interaction strength with BA acted as binding sites to induce the adsorption of aromatic ring on Ru NPs, leading to efficient hydrogenation of BA in hexane. To some extent, the phosphine could be regarded as the binding sites around $\mathrm{Ru}$ NPs in a similar way to those in enzymes. ${ }^{[2]}$ The promotion effect of phosphine ligand in BA hydrogenation was also observed using water as solvent (Table S3). In addition to hexane and water, Ru/PPh $\mathrm{Ph}_{3} @ \mathrm{FDU}$ also shows good to moderate activity in THF, dioxane, ethanol and isopropanol (Table S4). Furthermore, $\mathrm{Ru} / \mathrm{PPh}_{3} @ F D U$ had high recycle stability (Figure 3D).

In summary, the transformation from inactive to active state of Ru nanoparticles (NPs) for benzoic acid (BA) hydrogenation in organic solvent was achieved via simply tuning the microenvironment of the nanoreactor. Studies show that the phosphine ligands around Ru NPs induced the preferential adsorption of aromatic ring of BA on Ru NPs, which results in efficient hydrogenation of BA in hexane. In addition, our results showcased that the Ru NPs with enriched surface electrons are advantageous for the hydrogenation of aromatic ring, such as benzene, toluene and trifluorotoluene. Furthermore, the water effect in the hydrogenation was elucidated. The investigation of the microenvironment effect on the catalytic performance of nanoreactors is in progress in our lab. The encapsulation of active sites e.g. metal NPs in nanoreactors with precise microenvironment mimicking the process of natural catalysts is an efficient strategy to improve the catalytic performance of man-made catalysts for selective chemical transformations.

\section{Acknowledgements}

The authors are grateful to Prof. Can Li for fruitful discussions. This work was supported by the Natural Science Foundation of China $(21733009,21621063)$ and the Strategic Priority Research Program of the Chinese Academy of Sciences (XDB17020200). Jian Liu gratefully acknowledges the support of the Chinese Government 1000 Young Talent Plan.

Keywords: nanoparticle $\cdot$ hydrogenation $\cdot$ nanoreactor microenvironment $\bullet$ phosphine ligand

[1] S. Sadjadi, Organic Nanoreactors: From Molecular to Supramolecular Organic Compounds, Academic press, 2016, pp. 1-14

[2] J. B. Siegel, A. Zanghellini, H. M. Lovick, G. Kiss, A. R. Lambert, J. L. St.Clair, J. L. Gallaher, D. Hilvert, M. H. Gelb, B. L. Stoddard, K. N. Houk, F. E. Michael, D. Baker. Science 2010, 329, 309-313.

[3] S. Atsumi, T. Hanai, J. C. Liao, Nature 2008, 451, 86-89.

[4] L. C. Liu, A. Corma, Chem. Rev. 2018, 118, 4981-5079.

[5] X. L. Li, B. Y. Zhang, L. L. Tang, T. W. Goh, S. Y. Qi, A. Volkov, Y. C. Pei, Z. Y. Qi, C.-K. Tsung, L. Stanley, W. Y. Huang, Angew. Chem. Int Ed. 2017, 56, 16371-16375; Angew. Chem. 2017, 129, 16589-16593.

[6] Z. W. Wu, B. C. Bukowski, Z. Li, C. Milligan, L. Zhou, T. Ma, Y. Wu, Y Ren, F. H. Ribeiro, W. N. Delgass, J. Greeley, G. H. Zhang, J. T. Miller J. Am. Chem. Soc. 2018, 140, 14870-14877.

[7] Z. Y. He, B. Q. Dong, W. L. Wang, G. X. Yang, Y. H. Cao, H. J. Wang Y. H. Yang, Q. Wang, F. Peng, H. Yu, ACS Catal. 2019, 9, 2893-2901.

[8] X. Y. Liu, G. J. Lan, Y. Boyjoo, L. H. Qian, S. Gu, C. A. H. Price, L. Wang, Y. Li, J. Liu, Chem. Eng. J. 2019, 374, 895-903.

[9] L. C. Bai, X. Wang, Q. Chen, Y. F. Ye, H. Q. Zheng, J. H. Guo, Y. D Yin, C. B. Gao, Angew. Chem. Int. Ed. 2016, 55, 15656-15661; Angew. Chem. 2016, 128, 15885-15890. 
[10] R. Alamillo, A. J. Crisci, J. M. Gallo, S. L. Scott, J. A. Dumesic, Angew. Chem. Int. Ed. 2013, 52, 10349-10351; Angew. Chem. 2013, 125 10539-10541.

[11] Y. C. Chai, S. H. Liu, Z.-J. Zhao, J. L. Gong, W. L. Dai, G. J. Wu, N. J. Guan, L. D. Li, ACS Catal. 2018, 8, 8578-8589.

[12] J.-M. Ha, A. Katz, A. B. Drapailo, V. I. Kalchenko, J. Phys. Chem. C. 2008, 113, 1137-1142.

[13] K. R. Kahsar, D. K. Schwartz, J. W. Medlin, J. Am. Chem. Soc. 2013 136, 520-526.

[14] C. A. Schoenbaum, D. K. Schwartz, J. W. Medlin, J. Catal. 2013, 303, 92-99.

[15] S. H. Pang, C. A. Schoenbaum, D. K. Schwartz, J. W. Medlin, Nat Commun. 2013, 4, 2448.

[16] J. Zhang, L. Wang, Y. Shao, Y. Q. Wang, B. C. Gates, F.-S. Xiao, Angew. Chem. Int. Ed. 2017, 56, 9747-9751; Angew. Chem. 2017, 129 9879-9883.

[17] A. Heuer-Jungemann, N. Feliu, I. Bakaimi, M. Hamaly, A. Alkilany,I. Chakraborty, A. Masood, M. F. Casula, A. Kostopoulou, E. Oh, K. Susumu, M. H. Stewart, I. L. Medintz, E. Stratakis,W. J. Parak, A. G. Kanaras, Chem. Rev. 2019, 1198, 4819-4880.

[18] W. T. Cai, R. T. Mu, S. J. Zha, G. D. Sun, S. Chen, Z.-J. Zhao, Hao Li, H. Tian, Y. Tang, F. Tao, L. Zeng, J. L. Gong, Sci. Adv. 2018, 4 eaar5418.

[19] M. T. Zhao, K. Yuan, Y. Wang, G. D. Li, J. Guo, L. Gu, W. P. Hu, H. J. Zhao, Z. Y. Tang, Nature 2016, 539, 76-80.

[20] X. K. Wan, J.-Q. Wang, Z. A. Nan, Q. M. Wang, Sci. Adv. 2017, 3 , e1701823.

[21] H. G. Manyar, C. Paun, R. Pilus, D. W. Rooney, J. M. Thompsona, C Hardacre, Chem. Commun. 2010, 46, 6279-6281.

[22] X. Xu, M. H. Tang, M. M. Li, H. R. Li, Y. Wang, ACS Catal. 2014, 4 3132-3135

[23] R. F. Nie, H. Z. Jiang, X. H. Lu, D. Zhou, Q. H. Xia, Catal. Sci. Technol. 2016, 6, 1913-1920.

[24] M. H. Tang, S. J. Mao, M. M. Li, Z. Z. Wei, F. Xu, H. R. Li, Y. Wang, ACS Catal. 2015, 5, 3100-3107.

[25] B. N. Zope, D. D. Hibbitts, M. Neurock, R. J. Davis, Science 2010, 330 74-78.

[26] J. Saavedra, H. A. Doan, C. J. Pursell, L. C. Grabow, B. D. Chandler, Science 2014, 345, 1599-1602.

[27] L. R. Merte, G. W. Peng, R. Bechstein, F. Rieboldt, C. A. Farberow, L. C. Grabow, W. Kudernatsch, S. Wendt, E. Lægsgaard, M. Mavrikakis, F. Besenbacher, Science 2012, 336, 889-893.

[28] J. A. Anderson, A. Athawale, F. E. Imrie, F.-M. Mc Kenna, A. M. Cue, D. Molyneux, K. Power, M. Shand, R. P. K. Wells, J. Catal. 2010, 270,9 15.

[29] Z. Zhao, R. Bababrik, W. H. Xue, Y. P. Li, N. M. Briggs, D.-T. Nguyen, U. Nguyen, S. P. Crossley, S. W. Wang, B. Wang, D. E. Resasco, Nat Catal. 2019, 2, 431-436

[30] X. M. Zhang, Y. P. Zhao, S. T. Xu, Y. Yang, J. Liu, Y. X. Wei, Q. H. Yang, Nat. Commun. 2014, 5, 3170.

[31] S. Y. Bai , B. Li, J. Peng, X. M. Zhang, Q. H. Yang, C. Li, Chem. Sci. 2012, 3, 2864-2867.

[32] B. Li, S. Y. Bai, X. F. Wang, M. M. Zhong, Q. H. Yang, C. Li, Angew Chem. Int. Ed. 2012, 51, 11517-11521; Angew. Chem. 2012, 124 11685-11689.

[33] S. F. Zhang, B. Zhang, H. J. Liang, Y. Q. Liu, Y. Qiao, Y. Qin, Angew. Chem. Int. Ed. 2018, 57, 1091-1095; Angew. Chem. 2018, 130, 1103 1107.

[34] M. W. Wang, Y.Boyjoo, J. Pan, S. B. Wang, J. Liu, Chin. J. Catal. 2017 38, 970-990.

[35] D. M. Vriezema, M. C. Aragonès, J. A. A. W. Elemans, J. J. L. M. Cornelissen, A. E. Rowan, R. J. M. Nolte, Chem. Rev. 2005, 105, 1445 1490.

[36] J. Gaitzsch, X. Huang, B. Voit, Chem. Rev. 2016, 116, 1053-1093.

[37] G. Prieto, H. Tüysüz, N. Duyckaerts, J. Knossalla, G.-H. Wang, F. Schüth, Chem. Rev. 2016, 116, 14056-14119.

[38] M. Guo, H. Li, Y. Q. Ren, X. M. Ren, Q. H. Yang, C. Li, ACS Catal. 2018, 8, 6476-6485.

[39] S. Y. Chin, C. T. Williams, M. D. Amiridis, J. Phys. Chem. B 2006, 110, $871-882$.
[40] K. Hadjiivanov, J.-C. Lavalley, J. Lamotte, F. Maugé, J. Saint-Just, M. Che, J. Catal. 1998, 176, 415-425.

[41] H. Shinkai, K. Toi, I. Kumashiro, Y. Seto, M. Fukuma, K. Dan, S. Toyoshima, J. Med. Chem. 1988, 31, 2092-2097.

[42] B. S. Moore, H. Cho, R. Casati, E. Kennedy, K. A. Reynolds, U. Mocek J. M. Beale, H. G. Floss, J. Am. Chem. Soc. 1993, 115, 5254-5266.

[43] L. Foppaa, J. Dupont, Chem. Soc. Rev. 2015, 44, 1886-1897.

[44] C. A. Schoenbaum, D. K. Schwartz, J. W. Medlin, Acc. Chem. Res. 2014, 47, 1438-1445. 


\section{COMMUNICATION}

The nanoreactor modified with phosphine ligand enabled the efficient hydrogenation of benzoic acid (BA) over Ru Nanoparticles in organic solvent under mild condition which cannot be achieved in unmodified nanoreactors, owing to the phosphine ligands can manipulate the adsorption strength of BA on Ru NPs.

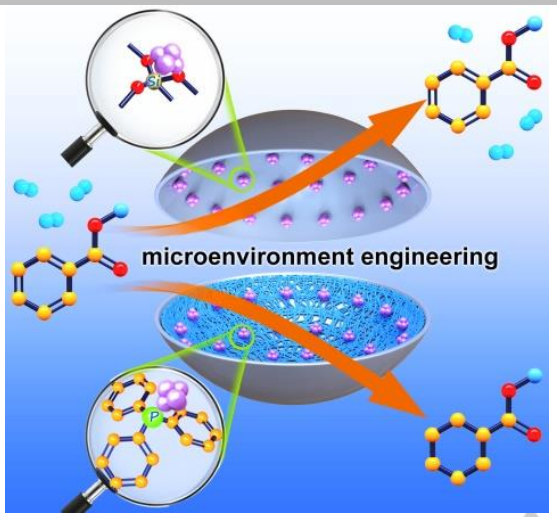

Xiaomin Ren, Miao Guo, $\mathrm{He} \mathrm{Li}$, Chengbin Li, Liang Yu*, Jian Liu*, Qihua Yang*

\section{Page No. 1- Page No.5}

Microenvironment engineering of $\mathbf{R u}$ nanoparticles incorporated in silica nanoreactors for enhanced hydrogenations 